\title{
Philosophical speech act theory and challenges in interactive dialogue: Experiences of narrow com- munication
}

\author{
Halvor Nordby \\ The University College of Lillehammer \\ PO Box 952 \\ 2604 Lillehammer \\ Norway \\ E-mail: halvor.nordby@hil.no \\ and \\ The University of Oslo \\ Department of health and society \\ PO Box 1089 Blindern, 0317 Oslo \\ Norway \\ E-mail: halvor.nordby@medisin.uio.no
}

\begin{abstract}
Background. Modern information conveying technology can facilitate interactive communication that transcends the possibilities of information exchange in ordinary face-to-face dialogue. However, interactive communication has its limits, related to lack of personal and physical closeness between communicators. When a communication channel is narrow - when written signs or verbal utterances are the only interpretive clues - misinterpretation and poor dialogue happens more easily than in face-to-face encounters. Design. The article analyses the concept of interactive narrowness on the basis of philosophical speech act theory and a study on interaction between paramedics and health personnel working in acute medical communication centers. Method. The article uses a combination of theoretical interpretation and experimental philosophy - philosophical analysis 'from below' - to develop a conceptual analysis of interactive narrowness that is grounded in actual experiences of this form of communication. Analysis. The paramedics held that it was difficult to secure interactive communication in hectic and unpredictable situations involving emotional disagreement and conflicts about choices of actions. Even when it was possible to discuss difficult situations on the phone, this could not replace face-to-face dialogue. Discussion. The paramedics' experiences support the conclusion that there is an irreducible interpretive element in face-toface dialogue that is not present in interactive communication. Speech act theory can shed further light on this irreducibility and, more specifically, on the importance of personal closeness in communication. Implications. Faceto-face communication is crucial in contexts that have similarities to the sensitive situations described by the paramedics. The article indicates how this and related implications apply in various settings and uses interactive dialogue between teachers and students in distance learning courses as an example area to clarify the main implications.
\end{abstract}

Keywords: Interactive communication, conceptual analysis, face-to-face dialogue, prehospital medical work 


\section{Introduction}

Interactive information exchange has become a dominant form of human communication, not only in our private lives, but also in pedagogical contexts such as dialogue between professional teachers and students (Keegan 1996, Caron 2007). Interactive communication and information conveying technology are used on all study levels - from primary schools to universities and in many further education courses. In fact, in some courses, typically sessionbased teaching for adolescents in distance learning arrangements, interactive classrooms constitute the main communication arenas (Katz et al 1999, Anderson 2008). Learning programs like Fronter ${ }^{i}$ and Its Learning ${ }^{\mathrm{ii}}$ are implemented and used as pedagogical tools over a large scale, often in combination with more common programs like Skype and Facebook (Saba \& Shearer 1994, Keegan 1996, Saba 2000).

These programs constitute structuring frameworks for interactive dialogue in the sense that they have many functions that are designed to secure successful exchange of thoughts and beliefs (Nordby 2006, Anderson 2008). Nevertheless, senders and audiences in communicative processes face many challenges of understanding when they are engaged in interactive discourse. The most obvious challenge is that communicators do not have full awareness of the context 'in the other end' - there is not the same kind of personal closeness and rich observational access as in ordinary face-to-face encounters (Nordby 2006, Bargiela-Chiappini \& Haugh 2010).

This absence of personal closeness is particularly striking in all the chatprograms that students use in further education settings, typically in group work. Students often exchange written messages on-line without visually observing each other, and this can make the communication challenging. In telephone calls a person's tone of voice can be of help (consider 'I can hear that he means to be ironic'), but it is limited how this can constitute a sound interpretive clue. In fact, even camera based programs such MSN and Kik cannot incorporate the quality of being present together. There is something that is simply not there. Even visual face-time communication channels are narrower than the rich observational context of ordinary face-to-face dialogue (Argyle 1988, Kappas \& Kramer 2011).

The first aim of this article is to use philosophical speech act theory to clarify how interactive narrowness influences the quality of human communication. The basic idea in speech act theory is that communicators use as little language as they think is needed in order to convey all the information they intend to communicate (Sperber \& Wilson 1986a, Cappelen \& Lepore 2006). According to this economical principle about communication, a large part of the message senders intend to transmit in communicative processes is underneath the surface of what they directly say. Senders typically hope, and they usually have good reason to believe, that communicative meaning that is not literally expressed ends up in the intended way in the consciousness of their audiences (Davidson 1987, Grice 1989, Bach 1994). This means that when communicators have limited interpretive clues, there is an increased probability that audiences form incorrect beliefs about the part of the message that is not directly expressed in language.

The second and main aim of the article is to discuss the significance of this implication by using results from a study on interactive communication between paramedics and ambulance coordinators in acute medical communication centers. iii The aim of the study was to understand how the paramedics experienced this communication, and how they thought it could be improved. A striking finding was that emotional and conflict related communication was conceived to be very challenging on-line. Poor interactive dialogue affected decision processes, cooperation and, in the final instance, the quality of the 
patient work. Within the framework of speech act theory and a modern empirical approach to conceptual analysis, the last part of the article uses these findings to elucidate the concept of interactive narrowness and to explain why it is so challenging to secure dialogue when communicators are not situated together in an ordinary face-to-face encounter.

\section{Forms of communication}

It is extensively documented that non-verbal behavior plays an important part in human communication (Bargiela-Chiappini \& Haugh 2010). It is difficult to measure exactly how communicators rely on non-verbal interpretation - how they use body language, facial expressions and other contextual factors as significant interpretive clues when this is possible (Argyle 1988). However, there is widespread theoretical and empirical agreement that personal closeness is vital in ordinary face-to-face communication (Hinde 1972, Baym et al 2004, Kappas \& Kramer 2011). When communicators are physically close and able to see each other, a variety of observations are essential in audiences' interpretations of senders' communicative intentions.

This kind of rich interpretational access is not available in interactive communication that is based on the use of modern information conveying technology like computers and mobile phones. ${ }^{\text {iv }}$ In email correspondence all that is visible to audiences is written signs. The communication channel is narrow - the communicative process does not have all the dimensions of ordinary face-toface encounters (Baym et al 2004, Nordby 2006). Interactive narrowness, in a fundamental sense, tightens the scope of human interpretation.

There are, obviously, degrees of narrowness. Misunderstandings in interactive communication are much more likely to occur when many communicative dimensions are missing. Thus, in communication involving text messages with many abbreviations it is more challenging to secure communication than in internet based communication involving web cameras (Kappas \& Kramer 2011). Both forms of communication are interactive, but the latter is not as narrow as the former. It reminds more of ordinary face-to-face dialog in the sense that communicators can see each other. Nevertheless, communication via web cameras is not as transparent as ordinary face-to-face dialogue: audiences can visually and audibly observe senders, but they are not situated together; they are not in the same three-dimensional interpretative room. All forms of interactive distance can make it challenging to achieve a full understanding of the context 'in the other end', and this can easily lead to uncertainty (and suspicion!) about senders' communicative intentions.

\section{Pedagogical experiences}

My own pedagogical experiences from a further education program for medical paramedics can serve as an initial illustration of the challenges in interactive communication. ${ }^{\mathrm{V}}$ In classroom discussions, our students often describe their interactive dialogue with ambulance coordinators in acute medical centers (AMK) ${ }^{\mathrm{vi}}$, via telephone or on-line written messages that are displayed on screens in ambulances and AMK. This communication can be stressful and hectic. Patients transported in ambulances are often critically ill or injured, it is difficult to secure proper assessment and treatment, and decisions must be made quickly. Nevertheless, the paramedics and AMK personnel sometimes disagree about choices of actions, and it is difficult to secure a shared, rational understanding of the situations the paramedics confront (Tjora 1997, Berlin \& Carlström 2009, 2011). 
These contextual factors can easily lead to misunderstandings, and many paramedics have negative experiences from their communication with ambulance coordinators in AMK. As one said: 'I do not trust him [a particular coordinator]. We have had many conflicts. So now, when he says [my italics] nice things like You did a good job' I typically think he is smiling ironically to the others in the control room [in AMK] when he is talking to me.' Another paramedic student analyzed the main challenge in an illuminating way:

\begin{abstract}
The problem is that we never see them [the AMK personnel]. So we ask ourselves: what are they doing in the other end of the line? Are they shaki ng their heads and rolling their eyes while they are talking to us? We get suspicious. We know what we do not have good reason to, but it is so difficult. The suspicion seems to come naturally. Perhaps we are born like this.
\end{abstract}

This is, in fact, a quite general attitude. In a comprehensive study on the relation between paramedics and telephone operators in AMK, Tjora (1997) found that places where the cooperation worked well were places in which paramedics often visited AMK after having delivered patients at the hospital where AMK was situated:

The contact is maintained through regular visits [in AMK]. The paramedics and the personnel in AMK really get to know each other. There is a friendly, open atmosphere. In coffee breaks they talk to each other, tell jokes and laugh together (Tjora 1997, p. 103).

A key to successful interactive communication was that the paramedics and AMK personnel learned to know each other as persons. But this happened in the face-to-face encounters. These encounters created bonds of trust and respect - both parties achieved a shared understanding that made them feel comfortable about discussing difficult issues in interactive contexts. This development of trust and interpretive competence could not be documented in places where paramedics and AMK coordinators never met. ${ }^{\text {vii }}$

This importance of face-to-face encounters, as described by Tjora, is striking. Nevertheless, the relation between paramedics and AMK is just one example of how it is difficult to secure communication in interactive contexts. It has, more generally, been extensively documented that observational togetherness is crucial for securing dialogue in emotional, conflict related and other forms of challenging communication (Argyle 1988, Baym et al 2004, Kappas \& Kramer 2011). The point is simply that interactive narrowness makes it challenging to talk about difficult issues.

These challenges in interactive dialogue can be elucidated from many perspectives, and it seems, at least prima facie, unreasonable to assume that one perspective is more sound than the others. A better suggestion is that various theoretical, empirical and practical analyses jointly can shed light on crucial distinctions between face-to-face and interactive communication. My first explanatory focus here will be a cognitive perspective from modern philosophy of mind and language. I will argue that speech act theories - theories of how language acts are used to express complex communicative intentions - are plausible frameworks for explaining why there are so many pitfalls in interactive communication.

\title{
Speech act theory
}

The basic idea in speech act theory is that written or spoken language acts is only the tip of the iceberg in human communication (Sperber \& Wilson 1986a, Bach 1994, Recanti 2004). Senders mean much more than what they strictly 
speaking say, and successful dialogue depends on audiences being right about the part of the message that is beneath the surface (Grice 1989, Cappelen \& Lepore 2006). This is part of the 'whole package' - the overall message senders intend to convey. Thus, part of the communicative message is only expressed indirectly, not literally in words that the sender uses. An imagined example can serve as an introductory explanation of how this can lead to poor communication:

A student has a meeting with his supervisor. They are discussing the progress of the student's work on his master thesis, and the supervisor sums up his comments by saying 'I think this is beginning to look very good'. This kind of appraisal is usually remembered well, so also in this case. After the meeting the student thinks about the conversation and what the supervisor said. He is confident that the supervisor is very pleased with his work, that she will recommend that he should submit his master thesis quite soon and that he will probably get a good grade.

In this example, we can imagine, the student's interpretation of the supervisor's views on submission is incorrect: The supervisor thinks that drafts of parts of the thesis are good, but that much more work is needed before the thesis should be submitted. If the student had asked the supervisor directly, she would have recommended that the student should submit next term.

The communication between the teacher and the student involves an associative misunderstanding: the associations the student forms about the sentence 'I think this is beginning to look very good' differ from the teacher's associations. Their contextual interpretation of what the supervisor strictly speaking says (the tip of the iceberg) is not the same: The student ascribed to the supervisor beliefs (part of the message beneath the surface) that were much more specific and positive than the beliefs the teacher actually associated with the sentence.

We can all recognize similar examples from our everyday communication. It is not uncommon that the language we use is not interpreted in the way we intend it to be understood. When we think we have good reason to believe that this might happen we typically try to clarify how we want to be understood. We put into words the full conceptual meaning of the message we intend to convey. So why does not the supervisor in the above example clarify what she means, in order to avoid unintended interpretations and associative misunderstandings? The reason, we can assume, is that the supervisor thought she was entitled to believe that the student would understand her as she wanted to be understood. She thought that her wider interpretation of her own speech was a natural interpretation, an interpretation she had prima facie reason to believe that the student would form as well.

If we had asked the supervisor, she would probably have said that it was unreasonable to interpret her in the way the student did. In other words, if the supervisor thought that the student's interpretation was reasonable (and thereby an interpretation she had good reason to believe that the student would form), then she would typically have clarified her own wider interpretation of what she said, to make is clear how she wanted to be understood, so that she could avoid the misunderstanding.

\section{The economical principle of communication}

The supervisor example is, obviously, just one example of an interpretive misunderstanding - a situation in which communicators interpret language acts in very different ways. This happens all the time - in our private and professional lives - and all these cases of poor communication can be explained in 
the light of speech act theory and what Sperber and Wilson (1986b) call an 'economical principle' about communication.

When communicating humans automatically aim at maximal relevance, i.e. maximal cognitive effect for minimal processing effort. This is the single general factor which determines the course of human information processing (Sperber \&Wilson 1986b, p.160).

There are other versions of this principle than the one Sperber and Wilson formulate (Bach 1994, Recanti 2004, Cappelen \& Lepore 2006), but the basic idea is the same: Language is used as actions to express complex intentions, and the main reason why we often misunderstand each other is that we only use as little language as we think we need - as few (economical) resources as we think is required - to convey all that we want to communicate (Grice 1989, Bach 1996, Carston 2002).

The economical principle has been widely recognized as a natural framework for understanding real-life communicative acts (Peacocke 2007), and it is not difficult to understand why many theorists have thought that the principle is plausible. In ordinary communication it would take an enormous amount of time (resources) for senders to put into words all they intend to convey to their audiences. Senders therefore attempt to formulate only what they think is needed in order to communicate all that they want to communicate.

Sperber and Wilson (1986a) give striking examples of how what they call loose talk' - use of utterances that are not strictly speaking true - might be the best way of communicating complex intentions. They imagine situations of the following kind:

Marie lives just outside Paris. At a cocktail party in England Peter asks her where she lives. Marie answers 'I live in Paris'. Sperber \& Wilson (S\&W) claim that even though Marie's sentence expresses a proposition that is literally false, it is correct of her to utter that sentence in the context in the following sense: from Marie's answer Peter will normally infer a substantial amount of true information, that Marie spends most of her time in the Paris area, that she lives an urban life, that Peter might try to meet her the next time he is in Paris, etc. But Peter will not infer that Marie lives in the city of Paris rather than just outside. The reason is, S\&W hold, that Peter (and Marie) knows that her answer can be used in the way Marie used it, as the most economical way of getting someone to make the inferences Peter makes and which are the inferences Marie wants him to make.

On the other hand, if Marie answers 'I live just outside of Paris', then S\&W hold that Peter is entitled to think that Marie wants him to know that she lives a suburban life, that she has to travel by train every day to get to work, etc. But these are not inferences Marie wants Peter to make (we can even imagine that some of them are false). Marie knows that Peter would make such inferences and therefore she chooses the first answer. "In other words, it is not just that Marie's first answer, 'I live in Paris', is effective enough to convey just what she wants; it may be more effective than the literally true second answer" (S\&W 1986a, p.164).

I have presented this example in length because it gives an illuminating illustration of how the economical principle applies in real life. It is, more generally, not difficult to understand why the principle provides an overall explanatory framework for analyzing communication. It can explain successful communication (communicators do not form very different associations), but also poor communication (communicators form very different associations). The latter happened as in the imagined supervisor case above, but the point is gen- 
eral. As Davidson (1987, p. 449) observes, interpretation "rests on vast vague assumptions about what is and what is not shared." Poor communication typically happens when an audience mistakenly thinks that his wider interpretation of a senders speech acts correspond to the senders' interpretation - that they share the same interpretative framework. As the supervisor example illustrated, this is not always the case. Our understanding of others are shaped by many idiosyncratic factors - such as our personal values, socio-cultural roles and individual horizons - and these factors can influence interpretation in many ways (Nordby 2008).

\section{Experiences of interactive communication}

Above I gave an initial description of how paramedic students struggle to secure communication with AMK. In order to achieve a more fundamental understanding of why interactive communication can be so challenging, I will use results from a more systematic empirical study on interactive communication in ambulance services.

In 2012, as part of a comprehensive research project on cooperation and colleague support in acute medicine, researchers from Lillehammer University College did a qualitative study on paramedics' experiences of prehospital communication. An important aim of the study was to understand how paramedics on assignment experience their interactive communication with telephone operators in AMK. The main reason why we wanted to do research on this relation was that we had heard critical comments of the kind described above. In classroom discussions and written work, many of our paramedic students working in ambulance services had expressed frustration about their communicative relation to AMK. Many described the interactive communication as 'far from optimal'.

For the purpose of getting more systematic knowledge of how this communication was perceived, we decided to interview paramedics students in one of our study courses - National paramedic program - a further education program for ambulance workers. ${ }^{\text {viii }}$ Students in this program have (minimally) certificate of completion as ambulance workers - or an equivalent competence - and they usually have extensive experience from many years in prehospital services.

\section{Conceptual analysis}

The interviews with the students were merely one element in a more comprehensive research project, and it would fall outside the limits of this article to present the project in detail. Furthermore, the aim here is not to present representative results from the study in an argumentative way. If that had been the aim, it would be necessary to clarify concepts of reliability and detailed methodological assumptions the study was based on. The more modest aim here is to use elements from the research to shed further light on the concept of interactive narrowness.

Doing this falls under the idea of conceptual analysis - of clarifying abstract concepts by understanding what they mean in our common language. Attempts to achieve this aim have traditionally been a priori - the analyses have attempted to define target concepts in terms of other concepts, independently of empirical investigations (Harman 1999). It is not, obviously, this kind of conceptual analysis that is relevant when actual experiences are used to illuminate a concept. The strategy I will purse here falls under a more modern way of doing conceptual analysis that is often called 'experimental philosophy' (Knobe \& Nichols 2008, Alexander 2012). The basic idea in this approach is 
that a concept cannot be fully understood simply by relating it to other concepts on the level of thought - as 'armchair metaphysics' (Sosa 2007). The concept must also be linked to the beliefs and thoughts people actually have about the concept's applications conditions. As Knobe and Nichols (2008, p.8) observe, "no experimental philosophers has ever offered an analysis of one concept in terms of another. Instead, the aim is usually to provide an account of the factors that influence applications of a concept."

The last decades have witnessed a growing skepticism about a priori conceptual analysis (Peacocke 2007, Burge 2010, 2013, Alexander 2012). Many philosophers have held that concepts definitions have to be tested against our linguistic intuitions, that such test are inductive (and hence empirical) in nature, and that our empirical intuitions about the meaning of concepts are, in themselves, shaped by our experiences (Harman 2009, Swain et al 2007, Systma 2010).

Experimental philosophy is a position that avoids these problems, and has thus become an influential approach to conceptual analysis in recent years. According to experimental philosophers, concepts should be saturated 'from below', on the basis of studies of how people normally understand them'. In this sense the aim is more modest than the aim of the traditional analyses. The intention is not to find necessary and sufficient conditions for the applications of concepts, but to elucidate - in a less rigid sense - central aspects of concepts in the light of actual experiences (ibid). As Knobe and Nichols (2008, p.5) observe, as long as "we can offer an account of the internal psychological processes that underlie our judgements, we do not need to find necessary and sufficient conditions for the application of the concept in particular cases."

Correspondingly, the aim of this article is not to develop a definition of what it means to communicate through narrow interactive information channels. The aim is to use the study of the paramedics' experiences as a platform for giving us a richer understanding of interactive narrowness. For this purpose, some striking findings from the study have been selected. In the presentation of these findings it will not be argued that they are representative for the professional group of paramedics as a whole. The aim is not to justify empirical conclusions, but to clarify interactive narrowness, and for this purpose it is sufficient to select findings that can help us to understand relevant communicative challenges.

\section{Method}

Invitations to participate in the study where sent out via email to students and paramedics who had graduated from earlier classes. The response was overwhelming. More than 100 paramedics wanted to participate, and 30 respondents were randomly selected for one-to-one in depth interviews. This group consisted of personnel with different backgrounds and various levels of competence skills. Some were working in rural areas, others in larger cities. All had in common that they were involved in interactive communication on a daily basis. The interviews also made it clear that the participants had many of the same views on interactive dialogue. No findings could be traced to differences related to personality or professional roles.

The interviews were made on the basis of standard naturalistic method in qualitative research (Bowling 1997, Flick 2002, Berg \& Lune 2012). The basic idea in the naturalistic approach is that literal interpretation is prima facie correct: Researchers are normally entitled to assume that informers mean what they say, that there is a direct link between their verbal statements their communicative intentions. According to naturalism, deviating from the principle of literal interpretation can sometimes be justified, but this requires a special justification. Literal interpretation is the norm and not the exception. 
For the purpose of understanding the paramedics' experiences, the study used narrative interviews. The idea in this approach is that informants' own stories and descriptions of events constitute a guiding norm for how interviews should be structured. A narrative approach is, as Flick (2002, p.96) observes, suitable when the topic of discourse are sensitive issues that cannot be captured within an ordinary question-answer scheme: "The starting point is a basic skepticism about how far subjective experiences may be tapped in the question-answer scheme of traditional interviews, even if this is handled in a flexible way." If interviews are designed as a list of questions it becomes difficult to capture informers' genuine experiences of complex social relations. Furthermore, informers can easily get an impression of being cross examined and forced into frameworks of interpretation that do not fit their idiosyncratic perspectives.

A rigid interview guide will necessarily have a narrow interpretive focus. By using a wide narrative approach it is possible to focus holistically on informers' overall horizons. As Flick observes, "Narratives allow the researcher to approach the interviewee's experiental world in a comprehensive way". Open questions give informers the possibility of engaging in reflection, so that they can identify their own opinions and find a language they think is suitable for expressing their views. The interaction there and then between researchers and informants can be meaning stimulating encounters that help the informants to develop their perspectives contextually. Bowling (1997, p.341) states the point in an illuminating way:

\begin{abstract}
With structured interviews, conducted within a framework of positivism, the interview-respondent interaction is of interest only in relation to interviewer bias and error, response bias and whether the interviewer has departed from the interview protocol. In contrast, unstructured interviews are regarded by qualitative researchers as a social encounter.
\end{abstract}

Within qualitative research, relational and contextual aims of understanding fall under a reflective life world approach (Dahlberg et al. 2001): Researchers aim to understanding what the world looks like from informers' perspective. As Neuman (2011, p.214) points out, the aim is to capture "an inside view and provide a detailed account of how the people we study understand events".

It is, obviously, impossible to get into other persons' subjective perspective. Nevertheless, the aim of understanding others' perspectives from the inside (from the outside) can be a methodological ideal. In accordance with principles from theoretical hermeneutics, reflective life world research is a useful holistic strategy for uncovering informers' subjective horizons, their overall perspectives on themselves and the world around them (Bowling 1997, Flick 2002). A personal horizon includes much more than thoughts and beliefs. It also includes mental states like emotions, attitudes and personal values. In order to facilitate comprehensive authentic communication, interviewers need to create an atmosphere that facilitates dialogue about all aspects of informers' horizons.

\title{
Findings
}

The participants included ambulance personnel with various backgrounds, identities and professional roles. One might therefore think that they would describe their dialogue with AMK very differently. This hypothesis turned out to be false. A striking finding of the study was that the paramedics shared many views about their interactive relations to AMK, and that they all described the interactive dialog as difficult and challenging. As one said: 'Misunderstandings happen very often. It seems impossible to avoid them. I have no idea what I should do.' 
Furthermore, it was a widespread view that the communication was poor because it was interactive and because the AMK personnel could not observe the patients directly. The following was a representative statement: The reality is often very different from what we think. So we face a double challenge: We do not know what to expect when we arrive at the scene of an accident. We have to prepare for the worst. But then we also have to communicate this to them [AMK], so they can make their decisions. The problem is that they do not see the patient and the situation, so this can be very difficult.'

\section{Conflicts}

When asked to explain why they thought the communication with AMK was so challenging, it was no surprise that the paramedic students did not use theoretical concepts from speech act theory. However, they clearly had an implicit understanding of the general idea about communication as involving much more than what is directly said. That is, they recognized that the main communication problem was that they did not interpret spoken or written messages - the 'visible' part of the iceberg - in the same way as the telephone operators in AMK.

The paramedic students said that it was not uncommon that they disagreed with AMK about choices of actions. Such disagreement could typically involve disputes about delivery addresses, resource allocations, patient autonomy and interpretation of information. When it was difficult to achieve agreement about these issues, conflicts sometimes arose. As one said:

Sometimes disagreement is settled when one of us [the ambulance or AMK] get new factual information, like an updated medical record. In such cases the communication problems are not so fundamental. The real problems arise when there is no new information that can help us to reach agreement. These disputes are not settled easily.

It was evident that many of the conflicts had normative dimensions - they involved disagreement about answers to question concerning what the ambulance personnel or AMK operators ought to do. As with normative questions in general, they did not have obvious empirical answers.

It was interesting to note that all the paramedic students held that it was especially difficult to solve these interprofessional normative conflicts as long as the communication was interactive. A typical view was that 'It is not so difficult with co-workers, like doctors, at the scene of an accident. It is so much harder on a busy telephone line.' The paramedics gave two reasons for this. First, limited time and resources made it practically difficult to discuss challenging situations over the phone. This was described as 'unfortunate', since extensive communication in conflict situations was conceived to be of special importance in interactive communication. As one said, We need time to reach agreement so that we can cooperate. In fact, we need more time when we cannot see each other. But this is hopeless in our job. It is sad to say, but sometimes we just hang up when we realize that we cannot understand each other.' Consequently, many conflicts were left unsolved and contributed to creating a negative tension between the paramedics and AMK operators.

The other reason why interactive communication made it difficult to solve normative conflicts was that the interactive context often created what one paramedic described as a bad atmosphere'. Intercom equipment was not thought to be a good channel for discussing conflicts. The technological distance made it difficult to focus rationally on arguments for and against alternative choices of action: 'We easily focus on the person we talk to instead of the 
issue we should discuss. This, I think, is because we do not really trust the person in the other end.'

Many of the paramedics said that they believed that it would have been better if they had met and learned to know the telephone operators in AMK. One paramedic student said about one of the ambulance coordinators: 'We talk very often but I do not know him, I have never seen him, and then I tend to forget that he is probably a nice guy. I have absolutely no idea of what kind of person he is. He could, for all I know, be a machine.' In fact, this student said that the associations he was disposed to form about the coordinator were probably not justified. When he thought about the coordinator from what he described as a more 'sober perspective', he 'was not confident' that some of the negative attitudes he ascribed to him corresponded to the attitudes the coordinator actually had.

Many paramedics talked about the phenomenon of 'talking past each other', and they said that this often happened in conflict situations. As a good example, one paramedic mentioned an episode in which he and his colleague had volunteered to assist at the scene of an accident.

We had transported a cancer patient to a centralised hospital far away from our station. We were driving back to the station when we heard on the radio that there had been a big car accident on one of the large highways, not too far away from where we were now driving on a smaller road. This was outside our geographical area of responsibility, so we were not obliged to redirect our resources, and AMK did not ask us to assist. However, there were no other assignments waiting for us, and the other ambulance in our station was free to go out, so we offered our assistance. After a short time AMK got back to us and said that we were not needed. We were surprised and wondered why. At first we thought, somewhat typically, that the reason was that they did not trust our competence and wanted to get in the heavy armour instead of our services from a smaller district station. This interpretation got us really annoyed, as so many times before [when communicating with AMK]. It was also typical, I must admit, that we later got new information that showed that our initial interpretation was false. It turned out that there were many more resources directed towards the accident than we knew, and that they were closer [in driving time] than we thought. So our irritation was not really justified. Why do we never learn?

I have quoted this story in length because it so clearly illustrates the point about the significance of knowledge of other persons underlying communicative intentions. If the paramedics had known more about the coordinator's intentions in the first place, they would not have formed the beliefs they did. Thus, it is evident how the theoretical framework from speech act theory can explain the misunderstanding. When the ambulance coordinator in AMK used the speech act 'Your assistance is not needed' (the visible part of the iceberg), he did not mean to convey doubt (as a part of the iceberg beneath the surface) about the paramedics' competence. The coordinator, we might assume, did not believe that the paramedics' competence was below required standards. When the paramedics mistakenly ascribed this belief to the coordinator, an associative misunderstanding happened (Davidson 1987, Nordby 2006). The associations the paramedics formed about the coordinator's message did not corre spond to the associations the coordinator had and meant to communicate.

Fortunately, in this situation the misunderstanding was uncovered. If this had not happened, there is a good chance that the poor communication would have contributed to developing - or maintaining - a negative relation between the paramedics and the coordinator. The paramedics saw this themselves: 'We thought they were sitting there making fun of us because we are from a district 
service and do not perform complicated procedures like intubation very often.' When the ambulance coordinator in AMK provided the further explanations, he did not only improve the communication there and then. He also prevented the misunderstanding from having negative consequences in the long run.

\section{Emotional communication}

In addition to conflict related communication of thoughts and beliefs, the paramedic students emphasized that the communication with AMK had an emotional element: 'We are persons, not computers, and we react in various ways to situations involving critically ill and sometimes dying patients'. Many assignments were experienced as having a heavy personal impact. The problem was that interactive communication channels were not conceived to be appropriate for discussing what one student described as the 'human factor in our relation'. This became especially salient when the paramedics experienced negative emotions like frustration, irritation or even anger. As one said, 'How can we talk about personal reactions on the phone with people we have never met?' The negative emotions the paramedics described were of three types, depending on their directions.

Personal coping. Some emotions were purely subjective - perceived to be personal reactions after difficult transports. These subjective feelings were not experienced as attitudes like anger, frustration or irritation directed towards other persons. They were directed inwards, 'into myself' as one said. A typical statement was, 'After difficult transports I often have a reaction. I take it personally.' This could typically happen after big accidents, but also after 'quiet difficult' assignments like transports of dying cancer patients (Nordby \& Nøhr 2011). Such transports were very challenging, but the paramedics very seldom talked about them with the AMK personnel. In fact, even when they talked to AMK after emotional assignments like transports of dying patients, the tone was described as formal and business like. The paramedics and the ambulance coordinators in AMK did not discuss personal difficulties or support each other, and this was attributed to the interactive context. As one paramedic said: When the person listening is an unfamiliar voice in the other end of a phone, it is difficult to talk about this'. Some paramedics mentioned body contact as crucial after emotional work: 'Sometimes we just need someone who can hold an arm around us. The phone is simply not the same.'

External relations. A second kind of emotions was directed towards coworkers from other professions, like personnel from the police and fire brigades. Many paramedics mentioned as typical examples emotional states like frustration or irritation, arising from poor cooperation on the scene of big accidents. Time pressure and acuteness of situations often resulted in emotional communication between the emergency personnel. In these situations it could be very difficult to find and maintain appropriate roles, respect leadership and getting updated information concerning cooperation and allocation of resources. Many of the paramedics missed more support from AMK. 'I know that it is not easy for them, but I would like to have more back up. Sometimes I think they could express a better understanding of the chaotic situations we are in, how difficult it is for us to get a good overview of the accident'. The paramedics said that they wished they could get more updated information from AMK and that AMK's communication could be better adjusted to the stressful and emotional prehospital work. ${ }^{\text {ix }}$ Again, this was connected to interactive communication and the lack of face-to-face meetings. AMK personnel could not see the difficult situations, and 'all the chaos and tension in the air' as one said. 
Internal relations. The paramedic students held that emotional communication was especially challenging when they experienced frustration, irritation or even anger in relations to medical doctors and the telephone operators in AMK. Supervising physicians who were formally responsible for patients were sometimes conceived to be arrogant and not always interested in cooperation. One paramedic said: We talk to them on the phone, but some of them think they always know best even though they have very little prehospital experience. They are not really interested in listening to us.' Once again, the paramedics blamed the interactive distance, and the fact that many of the doctors did not have a good observational understanding of the prehospital reality: They know medicine, but we see the patient and have many years of clinical experience.' Many paramedics were also dissatisfied with the practical information sent out by AMK. Patient descriptions were described as incomplete and difficult to understand, and individuals in AMK were conceived to be conflict shy and uncommunicative. One described an episode in which an irritated ambulance coordinator in AMK eventually said 'If you do your job, I will do mine'. This was not perceived as a positive comment, and it was regarded as particular unsuitable in an interactive setting.

J ust as the paramedics saw that their critical beliefs could sometimes be unjustified, they recognized that their emotional frustration was not always rationally grounded in facts and knowledge of the perspectives AMK operators have. As one observed, They have their sense of reality, I have mine. Deep inside I know that I have to understand before I can criticize. The problem is that it is so difficult when we live in separate worlds.' Another said that 'They are sitting in their control room deep down in the bunker. They nevertheless have an interactive overview that we do not have. We, however, are in the frontline and observe the patients directly. That can be difficult to remember, both for us and them [AMK]."

Not all the paramedics had a good understanding of this. When we asked them how they perceived the fact that the ambulances and AMK were working from different perspectives, some paramedics showed little or no awareness of the different professional roles and the limits and possibilities of information exchange. The majority, however, held that this was something they should I have in mind before criticizing AMK for making decisions that were objectively unsound. As one said: 'Criticism can only be justified if it is based on a good understanding in the first place'.

This statement deserves a special comment: it displays an impressive understanding not only of the distinction between understanding and justification, but also the deep philosophical dualism between communication and epistemology. In philosophy of mind and language, it has been a widespread assumption that questions of how it is correct to understand other persons should be distinguished from questions of who is right about an issue of dispute (Nordby 2005). Real 'authentic' agreement - agreement that is based on dialogue in which communicators are not talking past each other - presupposes a shared sense of meaning and reality in the first place. This is of particular importance in interactive dialogue: the communicative narrowness makes it easy to jump to conclusions based on insufficient knowledge due to the narrowness of the channel. Several paramedics emphasized that this was something it was important to acknowledge. They thought that being able to adjust their own communication to AMK's perspective should be part of their professional competence. Again, the emphasis was on learning to know each other and perspectives from the other side. 


\title{
Analysis
}

According to the idea of experimental conceptual analysis - as outline above actual experiences of a phenomenon can tell us something important about concepts that refer to that phenomenon, The idea is, as Knobe and Nichols (2008, p.4) observes, that 'Experimental philosophers proceed by conducting experimental investigations of the psychological processes underlying people's intuitions about philosophical issues' The target concept here is the concept of narrow interactive communication that does not involve an ordinary face-toface encounter. In this section I will show how the paramedics' experiences can shed illuminating light on communicative challenges in interactive settings.

It was striking how the paramedics' experiences of communication with AMK could be explained in the light of speech act theory. The paramedics held that the fundamental problem was that it was difficult to understand - and be understood - in 'the right way'. Both the paramedics and the AMK operators normally grasped the meaning of what was directly expressed. It was the associations underlying the messages literally expressed - displayed on a screen or heard on the phone - that were different.

All the paramedics held that the main problem was the communicative distance; that the narrowness of communication via telephone or on-line written messages constituted a fundamental obstacle to successful communication. Misinterpretation happened no matter how the paramedics tried to secure dialogue: the lack of interpretive clues made it impossible to avoid poor communication. Thus, the interviews with the paramedics support the idea that there is an irreducible element in face-to-face communication; that dialogue in which communicators are present together - in the same physical space - has a dimension that necessarily is absent in interactive communication.

Interpreted as a philosophical idea, this principle of irreducibility involves two claims about the essential nature of face-to-face communication.

\begin{abstract}
Metaphysical anti-reductionism. The first claim is that in face-to-face encounters there is a link between communicators that does not exist in interactive discourse. The idea is that the two forms of communication do not have the same ontological nature, in the sense that the aspect of togetherness in face-to-face communication is non-existing in interactive discourse. Metaphysical anti-reductionism implies that being together is an intrinsic property of face-to-face communication; the property exists independently of how we judge this kind of communication. This was accentuated in the study when the paramedics said that it was impossible to capture exactly what was missing in the interactive dialogue. It was something that just wasn't there.
\end{abstract}

Correspondingly, communicative anti-reductionism implies that togetherness is an extrinsic property of interactive communication. That is, no matter how interactive communication is designed to constitute togetherness, there will always be something missing: we might think we have managed to create a personal context, but the direct link is never there 'in itself', as what philosophers call a genuine 'primary' property (Stroud 2000). ${ }^{x}$

Epistemological anti-reductionism. The second claim of anti-reductionism concerns what we know, how our perspectives on the world relate to the world as it is, as opposed to how we think it is. ${ }^{\text {xi }}$ Epistemological anti-reductionism implies that we have cognitive access to something in a special irreducible way on one level of inquiry, and that this access is not available on other (lower) levels. Applied to the distinction between 
face-to-face and interactive communication, the idea would be that faceto-face communicators can achieve an understanding that they cannot reach in interactive contexts: while face-to-face knowledge of understanding is direct, understanding in interactive communication is mediated and indirect through information conveying technology. xii

All the paramedics claimed that it was problematic to understand the communicative intentions that the AMK operators expressed. The problem was partly that they represented a different professional culture, but the main challenge was the context of communication: The paramedics did not merely have (as they also have in face-to-face communication) indirect access to the operators' thoughts and beliefs. They also had nothing more than indirect access to vital interpretive clues - like nonverbal behaviour - that they could not see. All the limiting factors of the interactive dialogue made it difficult to form reliable interpretations.

\section{Actions and evaluative judgements}

The distinction between communicative anti-reductionism and reductionism has a striking parallel in theoretical ethics. Many philosophers have argued that we should make a deep distinction between theories asserting that ethical insight can be reduced to knowledge of moral rules (if you know and follow the rules your actions are good), and theories asserting that ethical insight must be based on a subjective competence that cannot be reduced to knowledge of rules. As Scott $(2003$, p.26) observes, the latter kind of ethical antireductionism has been become influential in the last few decades: " [A] number of contributors to the health care ethics literature have, for a number of years now, tried to argue that a virtue theory approach is needed at least as a supplement to a duty- and principle-based approach." According to critics of rule bases ethics, there is an awareness and subjective capacity of evaluative judgement that is irreducible; that cannot be described as empirical knowledge or learned like methodological tools or instructions in a manual (Nordby 2007).

The paramedics' experiences of interactive narrowness support the idea that actual evaluative judgements are irreducible in this sense. Rules or instructions could not solve disputes about solutions to ethical dilemmas; even when it was possible to talk extensively about choices of action, the discourse was conceived to be incomplete. The way the paramedics thought that an evaluative judgement was justified, could not be captured in words. Thus, the reason why the paramedics found it so difficult to solve ethical conflicts was that they found it hard to understand and convey ethical justifications. If communicating a justification had been a matter of conveying statements, then this would not have been so problematic.

\section{Closeness}

Ethical irreducibility is a general view, and we should distinguish this view from more specific explanations of why ethical justification cannot be reduced to rules. One influential explanation is that justification is connected to direct experiences of wanting to help other persons. In health work, this emphasis on closeness has often been connected to the French philosopher Levinas (1987) and his analysis of the appeal of the face:

The face forces itself on me, without it being possible for me to remain deaf to its summons or to forget it, that is to say making it impossible for me to cease being responsible for its helplessness. Consciousness no 
longer has priority ...To be I means from now on to be unable to escape responsibility.

It was precisely this closeness that the informers pointed to when they explained why the interactive narrowness made it so difficult to avoid conflicts about choices of action in patient work. The ethical insight was grounded in in face-to-face encounters with suffering patients, and these experiences could not be detached from the encounters. The conflicts were difficult to solve as long as the AMK operators did not have a direct understanding of what it was like to be there - looking into the eyes of patients who really need help. The paramedics thought that many conflicts could have been solved if the AMK operators had more experience from patient work.

\section{Ethics and communication}

Ethical dilemmas cannot be sharply distinguished from communicative challenges, but there is, nevertheless, a crucial difference between communication and ethics. In communicative practices we aim to convey thoughts and beliefs to others, in ethical practices we try to understand what it right and wrong. However, the practices also have a fundamental evaluative similarity. Communicating successfully is a matter of getting messages across in the intended 'right' way, just as ethical deliberation aims to understand what is morally 'right'. Furthermore, like analyses of communication, ethical inquiry focuses on actions. Ethical inquiry is more explicitly concerned with ordinary bodily actions, but use of language - not only speech acts - can also be evaluated as moral actions. In general, the scope of value evaluations includes all behavior that expresses intentional content.

This was clearly acknowledged in the study of the paramedics' experiences. When the paramedics focused on evaluations, they were not merely concerned with bodily actions in patient work. They were also concerned with the verbal utterances in the interactive dialogue. They were critical to many of the statements made by AMK, and they thought that they got undeserved criticism for saying what they did. A typical example was the abovementioned 'I do my job example'. This was conceived to be a statement that contributed to causing a conflict about the assignment. But it was also a conflict about how the utterance should be interpreted. The paramedics ascribed a negative value to the coordinator's speech act. The coordinator, on the other hand, thought that this was an appropriate remark (otherwise he would not have used it)

In other words, the interactive conflict had two levels. One concerned the assignment they were talking about, the other the speech acts they used to refer to that assignment. Both conflicts involved disagreement about values of actions, and both were difficult to address in the interactive setting. However, there was a crucial difference between them. The evaluations of the speech acts were evaluations about actions that could be directly observed. The discussions of actions in the patient work, on the other hand, were discussions of actions that AMK could not observe directly.

One might think that this would make a crucial difference, that the level of precision and possibility of agreement was better when the objects of discussion were transparent to both parties. This, however, was not the case. Conflicts and emotional communication were typically grounded in negative interpretations of others' speech acts, and the verbal conflicts were just as challenging as the conflicts about bodily actions. This finding really accentuates how fragile the interactive communication was: The problem was not merely that the paramedics and the AMK personnel misinterpreted each other in the sense that they had different perspectives on the reality of the patient work. The 
speech acts they used to talk about the patient work were also interpreted in entirely different ways.

\section{Personal coping}

I have so far focused on tensions in the interactive relations between the paramedics and the AMK personnel. As shown, the paramedics also said that the misunderstandings had a heavy personal impact. In order to get a richer picture of the communicative challenges in interactive dialogue, we should therefore say something about the psychological effects of the poor communication.

Fundamentally, all the paramedics agreed that the context created interpretive doubt. Furthermore, when they were uncertain about the AMK operators' motives, they tended to focus on negative interpretations. They ascribed negative attitudes to operators, even when they recognized that this was not justified. A striking example was the abovementioned situation involving an AMK operator who said 'Your assistance is not needed'. The paramedics suspected that the operator had doubts about their competence skills, but they also recognized, later on, that the statement could be, and probably should be, interpreted differently. The problem was that the context created a negative interpre tive filter; the communicative distance made it difficult to form more positive interpretations.

The negative interpretations created dissatisfaction and frustration on personal levels. This, in turn, led to a general tension, poor cooperation and a domino effect that influenced the quality of the patient work. What started as 'small misunderstandings' had large consequences. The paramedics recognized this, but they thought that their ascriptions of negative attitudes were a natural human reaction. And they blamed the interactive nature of the communication.

The other main problem related to the psychological consequences of the poor communication, was that it was difficult for others to see how the paramedics coped with assignments that had a heavy personal impact. The paramedics talked about debriefing as an example. They sometimes needed collegial support arrangements after emotional work, but understanding when this was needed was, to a large extent, a matter of observing a person's behavior. It was necessary to see the person. Talking to someone on the phone could not always reveal the need for a debriefing talk, and certainly not replace a real conversation about difficult transports. A debriefing arrangement should be a close personal encounter where those involved could share emotions and thoughts. All the paramedics agreed that when they really needed to talk to someone, it was important to be situated together.

\section{Pedagogical implications}

There are, obviously, many health related challenges in paramedic-AMK communication that are idiosyncratic - not salient in interactive communication in other professional relations. However, the results of the paramedic study, and the way they can be analyzed on the basis of speech act theory, are clearly relevant in other contexts. The interpersonal challenges described by the paramedics can arise in a variety of communicative relations involving comprehensive use of information conveying technology.

The nature of these challenges will vary, and it is difficult to develop substantial analyses on a general level. In order to clarify how the findings can shed light on interactive narrowness in other contexts, I will therefore focus on one area that is of special relevance in this journal, namely communication be- 
tween teachers and students in distance learning courses. Obviously, students recruited from professional services are not always involved in as much workrelated interactive communication as paramedics working in ambulances. However, like the paramedics in the national study program, students in adolescent courses and distance education typically use interactive communication extensively in their studies (Katz 1999). For the purpose of understanding the wider significance of the points made above, a natural area of generalization is therefore interactive communication related to studies for professional groups, in further education courses and other more or less formal pedagogical contexts. This is a wide area that involves a variety of communicative relations (Keegan 1994). For simplicity I will focus on the conceptual relation between 'teachers' and 'students'. It will be easy to understand how the implications I will outline apply to other learning relations, like interactive group work and other forms of communication between students.

The main implication is straightforward: as the initial student supervisor example above illustrated, students and teachers can sometimes misinterpret speech acts, and the use of interactive communication increases the risk of this happening. When narrow communication channels like chat programs or emails are used, it is more difficult for students to make reliable interpretations of how teachers express communicative intentions. Consequently, they can often form mistaken beliefs about the part of the communicative 'iceberg' that lies beneath the surface.

Obviously, when students and teachers do not meet very often, interactive classrooms are valuable arenas for dialog (Saba \& Shearer 1994, Saba 2000, Nordby 2006). But there are many pitfalls when senders and audiences are not present together, and this is why the paramedic students' experiences are so interesting. They not only illustrate how challenging it can be to secure successful communication in interactive contexts. More importantly, the study has practical and normative dimensions, in the sense that it indicates how interactive teacher-student communication can be improved. Four implications should be accentuated:

1. The paramedic study suggests that conflicts and emotional issues should, as far as possible, be discussed face-to-face. If it is not realistically possible to do so in a conflict situation, it is normally a good idea to arrange a face-to-face meeting later, when this is realistically possible. The interviews with the paramedic students indicate that if this is not done, unresolved tensions can have a negative impact on the teacher-student relation. Formal or informal 'debriefing' talks - in settings that all parties experience as comfortable - are important to clear the air. As the professional leader in the relation, this is something teachers need to pay special attention to. Students have normally no choice but to defer to teachers' way of organizing the communication. As the rule (and not the exception), creating a dialogue context that students are comfortable with, falls within teachers' area of responsibility.

2. Speech act theory has a normative implication for teachers in communicative processes: if they have reason to think that the beliefs they associate with a message are radically different from the beliefs students form, they should clarify their own associations, so that these associations end up in the consciousness of their audiences. Thus, if a teacher thinks that a student is about to misinterpret his speech acts, he should bring his own interpretation to the surface. In the supervisor example above, it was a good question whether the student's mistaken interpretation was a natural interpretation. It is, at any rate, clearly possible to interpret the rather vague sentence ' $\mathrm{I}$ think this is beginning to look very good' in various ways. This means that the principle of economical communication should be weakened from the perspec- 
tive of the supervisor. In order to avoid possible misunderstanding (and resource consuming) unintended consequences, she should have invested more time in clarifying her overall intentions. Using extra resources was especially important in the light of the fact that the misunderstanding could have substantial negative consequences.

3. The principle about uncovering associations also applies in the other way in pedagogical relations, when students are senders and teachers audiences. Speech acts expressed by students contain much more than what they directly say. They use what they regard as the most convenient way of conveying what they want to communicate, but their own interpretations of links between observable language and background intention is colored by their subjective perspectives - their social roles, values and cultural horizons of understanding. These horizons can be very different from their ('old fashioned?') teachers' horizons, and when the communication channel is interactive, it can be even more difficult for teachers to get a good understanding of students' communicative intentions. The implication for teachers is obvious: when there is good reason to interpret a student's speech act in a nonstandard way, they should seek to uncover the student's interpretation. Straightforward questions like Do you mean that...?' or 'Do I understand you correctly if you mean that...?' are often sufficient. Many unintended consequences of poor communication can be avoided if teachers have (interactive!) social antennas for noticing when such questions are appropriate.

4. Communication related to conflicts and emotional communication should be based on a shared understanding. A fundamental misunderstanding happens if two communicators who disagree about a topic of discourse are talking past each other - if the disagreement is based on an insufficient understanding of the other person's perspective. A typical example might be a case in which a student has received a lower grade on an essay than what he expected. Normally the student only sees the grade, and he might easily be wrong about his teacher's beliefs about the content of the essay. The student might, for instance, think that the teacher is not satisfied with his knowledge of the topic area. The teacher, however, might be satisfied with this but not so satisfied with the student's discussion. He might think that the essay lacks a good, independent voice and sound arguments.

Obviously, in 'authentic' two-way communication, all parties have a responsibility for securing dialogue. This principle also applies in the relation between teachers and students. However, there are two reasons why teachers have the primary responsibility for paying attention to the four conditions I have outlined. First, the relation between teachers and students is a professional, formalized relation. It is therefore also part of teachers' professional duty to secure communication. ${ }^{\text {xiv }}$ Second, students are, even informally, often the 'weak' part. The psychological dynamics of the relation can make it difficult for students to raise their voices and take the initiative to uncover possible misunderstandings and talk about what they regard as poor communication.

\section{Conclusion}

In this article I have used speech act theory and actual experiences of interactive narrowness to clarify challenges in communication that does not involve an ordinary face-to-face encounter. Obviously, much more could be said about these challenges, but that would fall outside the limits here. My aim has been to clarify the idea that there is an irreducible element in face-to-face commu- 
nication, and use this idea to explain why it is so challenging to secure communication in interactive settings.

The main challenge, I have argued, is that it is difficult to find the right words in narrow interactive settings. Furthermore, finding the right words and express all that is needed is, in the final instance, a matter of understanding what is right and wrong. In interactive communication it is especially important to choose one's speech acts carefully and to be aware of how audiences reads more into expressed messages than what is strictly speaking said. In formal relations such as the relation between teachers and students, this responsibility involves more than avoiding associative misinterpretation: Teachers need to be sensitive to idiosyncratic interpretations that students do not express directly in words, but they also have professional obligation to understand when interactive communication cannot substitute the closeness of a real faceto-face encounter.

\section{References}

Alexander, J. (2012). Experimental philosophy: An introduction. Cambridge: Polity Press.

Anderson, T. (2008). The theory and practice of online learning. Edmonton: AU Press.

Argyle, M. (1988). Bodily communication. London: Methuen.

Austin, J. L. (1961). How to do things with words. Oxford: Clarendon Press.

Bach, K. (1994): Thought and language. Oxford: Clarendon Press.

Bargiela-Chiappini, F. \&, Haugh, M. (2010). Face, communication and social interaction. Sheffield: Equinox publishing.

Baym N,K., Zhang, Y.B. \& Lin, M-C. (2004). Social interactions across media: Interpersonal communication on the internet, telephone and face-to-face. New Media \& Society,6(3), 299- 318.

Berg, B. \& Lune, H. (2012). Qualitative research methods for the social sciences. Boston: Pearson publishers.

Berlin, J . \& Carlström, E. (2009). Samverkan på olyksplatsen. Trollhättan: University West.

- (2011). Samverkan mellom blåljusorganisationar. Lund: Studentlitteratur.

Bezuidenhout, A. (2002). Truth conditional pragmatics. Philosophical perspectives 16, 105-34.

Boghossian, P. (2007). Fear of knowledge. Oxford: Oxford University press.

Bowling, A. (1997). Research methods in health: Investigating health and health services. Buckingham: Open University Press.

Burge, T. (2010). Origins of Objectivity. Oxford: Oxford University Press.

- (2013). Cognition through understanding. Oxford: Oxford University Press.

Cappelen, H., Lepore, E. (2006). Insensitive semantics. Oxford: Blackwell.

Caron, A.H. (2007). Moving cultures: Mobile communication in everyday life. Montreal: MoGill-Queen's University Press.

Carston, R. (2002). Thoughts and utterances: The pragmatics of explicit communication. Oxford: Blackwell.

Dahlberg, K, Dahlberg, H. \& Nyström, M. (2001). Reflective lifeworld research. Lund: Studentlitteratur 
Davidson, D. (1987). Knowing one's own mind. Proceedings and addresses of the American philosophical association, 61.

Flick, U. (2002). An introduction to qualitative research. London: Sage publications.

Freidsson, E. (1988). Profession of medicine. Chicago: Chicago University Press.

Grice, P. (1989). Studies in the ways of words. Cambridge, Mass: Harvard University Press.

Harman, G. (1999). Reasoning, meaning and mind. Oxford: Oxford University Press.

Hinde, R. A. (1972). Non-verbal communication. Cambridge: Cambridge University Press.

Kappas, A. \& Kramer, N. (2011). Face-to-face communication over the internet: Emotions in a web of culture, language and technology. Cambridge: Cambridge University Press.

Katz, R. N. and associates (1999). Dancing with the devil. Information technology and the new competion in higher education. San Fransisco: J ossey-Bass Inc. publishers.

Keegan, D. (1996). Foundations of distance education. London: Routledge.

Knobe, J . \& Nichols, S. (2008). Experimental Philosophy. Oxford: Oxford University Press.

Koprowska, J . (2010). Communication and interpersonal skills in social work. Exeter: Learning matters.

Levinas, E. (1987). Time and the other. Pittsburgh: Duquesne University Press.

Neale, S. (1990). Descriptions. Cambridge, Mass: MIT Press.

Neuman, W. L. (2011). Social research methods: qualitative and quantitative approaches (7th ed.). Boston: Pearson.

Nordby, H. (2004). Concept possession and incorrect understanding. Philosophical explorations, 2.

- (2003).Doctor-patient-interaction is non-holistic, Medicine, Health Care and Philosophy, 2.

- (2006). Face to face and interactive communication. Seminar.net, 3 (www.seminar.net).

- (2007). Wittgenstein's theory of conceptual competence and virtue analyses of ethical dilemmas in nursing practice. Online journal of health ethics, 1.

- (2008). Values, cultural identity and communication: A Perspective from philosophy of language. J ournal of Intercultural Communication, 17.

- (2011a). The nature and limits of interactive communication, Seminar.net, 1 (www.seminar.net).

- (2011b). Care and empathy in ambulance services: paramedics' experiences of communicative challenges in transports of patients with prolonged cancer. J ournal of communication in health care, 3-4.

Peacocke, C. (2007). Truly understood. Oxford: Oxford University Press.

Recanti, F. (2004). Literal Meaning. Cambridge. Cambridge University Press.

Saba, F. \& Shearer, R. (1994). Verifying key theoretical concepts in a dynamic model of distance education. The American journal of distance education, 8(1), 36- 59.

Saba, F. (2000). Research in distance education: a status report. International review of research in open and distance education. 1(1)

Scott, P. A. (2003). Virtue, nursing and the moral domain of practice. In V. Tchudin (Ed.) Approaches to ethics: Nursing beyond boundaries (p.25-32). Edinburgh/London: Butterworth-Heinemann. 
Sosa, E. (2008). Experimental Philosophy and philosophical intuition. Philosophical studies, 132(1), 99- 107.

Sperber, D. \&Wilson, D. (1986a). Loose Talk. Proceedings of the Aristotelian Society, 86, 153- 171

- (1986b). Relevance. Oxford: Blackwell.

Stroud, B. (2000). The quest for reality. Oxford: Oxford University Press.

Swain, S., Alexander, J. \& Weiberg, J.M. (2008). The instability of philosophical intuition. Philosophy and phenomenological research, 76(1), 138- 155.

Sytsma, J. (2010). “The Proper Province of Philosophy: Conceptual Analysis and Empirical Investigation."Review of Philosophy and Psychology, 1(3), 427- 445.

Tjora, A. (1997). Caring machines: Emerging practices of work and coordination in the use of medical emergency communication technology. D. Phil dissertation. Trondheim: NTNU.

\section{Endnotes}

i http:// com.fronter.info/

ii https:// www.itslearning.com/welcome.aspx

iii In Norway these centers are called 'AMK'. This is where you get if you dial medical emergency number (113 in Norway).

iv The distinction between face-to-face and interactive communication is not sharp. For the purposes here, we do not have to rely on a definition of the distinction. It is sufficient to rely on an intuitive conception. For a detailed discussion of how the concept of interactive communication should be defined, see Nordby (2011).

v $\underline{\text { http://hil.no/nasjonal_paramedic utdanning. }}$

vi Nurses working in AMK answer medical emergency calls and cooperate with ambulance coordinators who make practical arrangements related to the ambulance assignments. Paramedics in the ambulances units communicate extensively with the coordinators and sometimes with the emergency nurses.

vii The reason why some paramedics never met the AMK personnel was that they worked in ambulance services that never delivered patients to the hospital where AMK was situated. Paramedics who knew the persons working in AMK often transported patients to causalty centres situated close to the AMK central, and there was an informal culture of visiting AMK after patient delivery.

viii The program is session based and uses principles from distance education in be tween the sessions. For a general introduction to distance education, see Keegan (1996).

ix AMK normally gets updated information from the other emergency centrals - police and fire brigades - and it is usually possible for AMK to forward this information to the ambulance units when they are on their way to the scene of an accident. The paramedics appreciate this, as they become better prepared for the reality that awaits them.

x The direct link would then be a secondary property, in the same way colors and other relational properties have been thought of as partly subjective in nature (Stroud 2000)

xi Realism is the view that many objects and properties in the world around us exist independently of us. Realism goes hand in hand with fallibilism, the view that we can never know for sure that we think is true really is true. Nowadays, most philosophers are realists of some form (Boghossian 2007).

xii This idea about face-to-face directness has a parallel in theories of self-knowledge theories of how we have privileged access to our own conscious thoughts (Burge 2013). Obviously, we do not have direct first-person access to others' thoughts in face-to-face communication, but the principled distinction between directness and indirectness is the same: Epistemological anti-reductionism about communication claims that there is 
an asymmetry between direct face-to-face communication and indirect interactive communication.

xiii This typically happens when the misunderstanding leads actions that are inconsistent with the senders intentions. In the above example we might imagine that the student, as a consequence of the misunderstanding, starts to apply for jobs because he thinks he will soon graduate.

xiv It is also reasonable to assume that it is part of teachers' responsibility to talk to students about their relational communication. Clarifying this is often a key to avoiding conflicts. In fact, knowledge of communication principles can be helpful for teachers in two ways. The knowledge can guide them in their interaction with students, but they can also, somewhat more theoretically, pass the knowledge on to the students. 